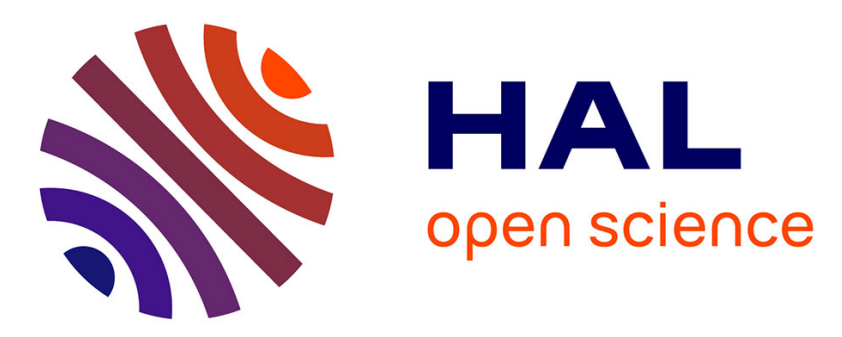

\title{
An open circuit voltage decay system for a flexible method for characterization of carriers' lifetime in semiconductor
}

Khaoula Amri, Rabeb Belghouthi, Michel Aillerie, Rached Gharbi

\section{To cite this version:}

Khaoula Amri, Rabeb Belghouthi, Michel Aillerie, Rached Gharbi. An open circuit voltage decay system for a flexible method for characterization of carriers' lifetime in semiconductor. Key Engineering Materials, 2021. hal-03216732

\section{HAL Id: hal-03216732 \\ https://hal.science/hal-03216732}

Submitted on 17 May 2021

HAL is a multi-disciplinary open access archive for the deposit and dissemination of scientific research documents, whether they are published or not. The documents may come from teaching and research institutions in France or abroad, or from public or private research centers.
L'archive ouverte pluridisciplinaire HAL, est destinée au dépôt et à la diffusion de documents scientifiques de niveau recherche, publiés ou non, émanant des établissements d'enseignement et de recherche français ou étrangers, des laboratoires publics ou privés. 


\title{
An open circuit voltage decay system for a flexible method for characterization of carriers' lifetime in semiconductor
}

\author{
Khaoula Amri ${ }^{1,2}{ }^{*}$, Rabeb Belghouthi ${ }^{1,3, b^{*}}$, \\ Michel Aillerie ${ }^{1, c}$ and Rached Gharbi ${ }^{3, d}$ \\ ${ }^{1}$ LMOPS, Université de Lorraine, CentraleSupélec, F-57000 Metz, France \\ ${ }^{2}$ LISIER, Université de Tunis, Tunis, 1008, Tunisie \\ ${ }^{3}$ LOMC, UMR CNRS 6294, Université du Havre, F-76600, Le Havre, France \\ a khaoulaomri2@yahoo.com, ${ }^{b}$ rabebbelghouthi@gmail.com, 'michel.aillerie@univ-lorraine.fr
}

\begin{abstract}
Keywords: Carrier lifetime; Automated system; Photoconductivity decay; Recombination mechanism; Open Ccircuit Voltage Decay.
\end{abstract}

\begin{abstract}
Among all the material parameters of a semiconductor, the lifetime of the carriers is one of the most complex, as it is a function of the dominant recombination mechanism, the number of carriers, the structural parameters and the temperature. Nevertheless, the lifetime of the carriers is a very useful and fundamental parameter to be determined for the qualification of the semiconductor in order to allow the improvement of the manufacturing process and the optimization of the operation of the semiconductor device. Thus being strongly linked to many physical and electronic parameters, the lifetime of the carriers cannot be provided only with a theoretical average value and an experimental measured value must be obtained. In the case of semiconductor junctions, precise measurements of the open-circuit voltage decay, OCVD, make it possible to trace the lifetime of the carriers through the device. An automated method for OCVD measurements presented in this contribution overcomes the main limitations that arise in the standard method when used for the characterization of the lifetime of carriers as it achieves the "open circuit conditions" of the device under test and reduces inherent noise of the differential operation mode of the method.
\end{abstract}

\section{Introduction}

Being the most important and significant material parameter of a semiconductor, the carrier lifetime, wich is defined as the average time it takes an excess minority carrier to recombine ,is extremely sensitive to smallest amounts of impurities or intrinsic defects[1]. In fact, the carrier lifetime depends on the material nature and the various treatments subjected by the device. It enables to produce solar cells with a suitable bulk thickness and doping levels which leads to devices optimization. Measuring the carrier lifetime allows device modelling [2]. Furthermore, by combining this information with wafer level lifetime measurements techniques it can be used as a process control metric [3]. Although Deep Level Transient Spectroscopy (DLTS)[4] is accepted as one of the most sensitive technique for detecting and analysing defects in $p-n$ junctions, it couldn't cover defects that exist in concentration below the detection limit of the method. Photodecay methods are employed both for investigation of the photoconductive materials and the photovoltaic structures [5], they are based on standard Shockley-Read-Hall theory (SRH) allowing a direct identification of impurities when the injection and temperature dependence of carrier lifetime are controlled [6]. They offer a very sensitive method for characterizing defects affecting carrier lifetime, and since the effective lifetime itself is the primary quantity measured, these methods can be utilized to fill in missing data about the recombination activity of particular defects in various semiconductors witch can't be obtained by DLTS methods. In order to precisely apply the photodecay method, the effective lifetime must be measured as exactly as possible. Thus, a 
complete system was developed which allow the injection of wide range of current levels and uses built-in data acquisition to receive the decay waveforms produced. The Open Circuit Voltage Decay (OCVD) method was employed with a relatively unique data extraction algorithm that circumvents the inherent abstraction of data and added noise caused by conventional methodologies.

\section{The Steady state (SSPC) and Quasi Steady-state (QSSPC) methods}

In the steady state conditions, the generation of electron - hole pairs is in balance with the recombination of the same pairs.

In the steady state conditions, the generation of electron - hole pairs is in balance with the recombination of the same pairs.

$$
\mathrm{G}=\mathrm{R}
$$

As a consequence, the photoelectric density Jph can be expressed in terms of an effective minority carrier lifetime $\tau_{e f f}$ and the minority carrier density $\Delta_{n}$ as:

$$
J_{p h}=(\Delta n q d) / \tau_{e f f}
$$

where $\mathrm{d}$ denotes the sample thickness.

The

minority excess carrier density $\Delta_{n}$ and the majority excess carrier density $\Delta_{p}$ allow determining the photoconductivity $\sigma_{p h}$ as

$$
\sigma_{p h}=q\left(\Delta_{n} \mu_{n}+\Delta_{p} \mu_{p}\right)=q \Delta_{n}\left(\mu_{n}+\mu_{p}\right)
$$

where $\mu$ is the mobility of the carriers

From (2) and (3), we can determine the effective minority carrier lifetime is given by

$$
\tau_{e f f}=\frac{\sigma_{p h} d}{J_{p h}\left(\mu_{n}+\mu_{p}\right)}
$$

If we modify the SSPC method described above and instead of using a constant illumination, we use a light pulse that varies slowly compared to the effective lifetime of the wafer, this method is called QSSPC [7]. It was introduced by Sinton and Quevas in 1966 [8]. The method permits obtaining the photoconductivity under a large range of illumination intensities in a short time without any significant sample heating. The quasi steady-state photo conductance data implicitly contain information about the short-circuit current versus the open circuit voltage.

The implicit voltage of a solar cell made on $p$-Type wafer with dopant density depends on the $\mathrm{p}$ $\mathrm{n}$ product at the junction is expressed as

$$
V_{o c}=\left(\mathrm{k}_{B} T / q\right) \ln \left[\Delta_{n}\left(N_{A}+\Delta_{p}\right) / n_{i}^{2}+1\right]
$$

where $n_{i}$ is the intrinsic carrier density, $\mathrm{k}_{B}$ presents the Boltzman constant and $\mathrm{T}$ is the temperature.

The local excess minority carrier density is obtained from Eq (3) when the surfaces of the sample are passivized and the minority carrier diffusion length exceeds the wafer thickness 
The QSS method was developed to measure simultaneously the open circuit voltage of the solar cells and the incident light intensity [9].

The effective lifetime of minority carriers can be determined from the measured $V_{o c}$ values:

$$
\tau_{e f f}=\frac{n_{i}{ }^{2} \exp \left(\frac{V_{o c}}{\mathrm{k}_{B} T / q}\right)}{J_{p h}\left(N_{A}+\Delta_{n}\right) / q d}
$$

The difference between the lifetime calculations based on Eqs (4) and (6) is the way in which the excess carrier density within the semiconductor is sensed.

\section{The extension of OCVD methods to photo-decay measurements}

Among the classical methods of semiconductor investigation, it is possible to apply the OCVD methods for the characterisation of the photocurrent decay (PCD), related to the carriers' lifetime as proposed by Stevenson and Keyes in 1955 [10], of course applied to photoconductor devices as photodiodes.

The photoconductor sample is uniformly illuminated by the light pulses inducing adequate generation of the excess carriers and photocurrent variation. The photocurrent is recorded as a drop of the voltage on the resistor connected in series.

Starting from the basic continuity equation in a simplified form:

$$
\frac{d p_{n}}{d t}=G-\frac{P_{n}-P_{n 0}}{\tau_{p}}
$$

At the steady state, $\frac{d p_{n}}{d t}=0$, and from Eq (7)

$$
P_{n}=P_{n 0}+Z_{p} G=\text { const }
$$

Turning off the light at $\mathrm{t}=0$, one can obtain the differential equation

$$
\frac{\partial P_{n}}{\partial t}=-\frac{P_{n}-P_{n_{0}}}{\tau_{p}}
$$

This has the solution,

$$
P_{n}(t)=P_{n_{0}}+\tau_{p} G e^{-t / \tau_{p}}
$$

An alternative method to measure the carrier lifetime is the microwave Photo conductance decay (MW-PCD). The principle of this technique is to excite the cell with a laser source (a short pulse of $100 \mathrm{~ns}$ ) generating the excess carriers within the wafer. Then; we measure the decay of the carrier concentration via the reflected microwave power [11].

Comparing the MW-PCD with the QSSPC technique, the second allows accurate lifetime measurements over large injection ranges in one quick flash. Moreover; the carrier injection level is measured with no need for any device simulation [12].

Another method for investigating the recombination parameters of solar cells is the open circuit voltage decay (OCVD) technique [13].

The method was first described by Leaderhandler and Giacoletto [14]. Its simplest form. The p-n junction is forward biased until it reaches a steady -state and then quickly switched off from the excitation source to leave the junction in real open circuit conditions, (we measure then the voltage drop over time). The voltage across the diode immediately drops by an initial amount $\Delta V$ due to the 
junction's internal series resistance, and then the voltage decreases (ideally, assuming no excessive parallel resistance or capacitance) due to recombination of the injected carriers.

The derivative of the voltage expression for a $p-n$ junction assuming asymmetrical doping is given by Equation (11).

$$
F(t)=\left[\frac{1}{\eta V_{t}} \frac{d V_{D}}{d t}\right]^{-1}
$$

with $\eta=1+p_{0} /\left(p_{0}+N_{D}\right)$ is the injection - dependent ideality factor which varies from 1 at low injection $\left(p_{0} \ll N_{D}\right)$ to 2 under high injection level $\left(p_{0} \gg N_{D}\right)$ is the doping concentration of the n-type layer, and $p_{0}$ depends on $V_{D}$, as

$$
p_{0}=N_{D} / 2\left\{-1+\left[1+4\left({n_{i_{0}}}^{2}\right) /\left(N_{D}^{2}\right)\right) \exp \left(V_{D}(t) / V_{t}\right)\right]^{\frac{1}{2}}
$$

that can be calculated with the value of the intrinsic carrier density $n_{i_{0}}$. For silicon semiconductors, the standard value of $n_{i_{0}}$ is considered as equal to $1.45 .10^{10} \mathrm{~cm}^{-3}$ at room temperature (Value providing from the datasheet of the diode Vishay 1N4007). Vt is the thermal voltage, which is equal to $25 \mathrm{mV}$ at room temperature.

\section{OCVD System hardware}

In order to measure the open circuit voltage decay with good accuracy an avoiding the joule heating effect of the junction, there with less noise affecting the signal, a new structure was set in place and build for the work presented here in

- Keithley 2400, [15] as controllable source for current injection that can operate by a pulse signal to avoid joule heating.

- Semelab D2081UK MOSFET that is controlled by an HM8030 HAMEG pulse generator [16] to disconnect the DUT from the source current.

- HM8030 HAMEG pulse generator

- An oscilloscope Tektronix TDS 220 [17] to acquire data quickly.

- A control section that is connected to the oscilloscope via GPIB, which manages signals and calculates the carrier lifetime.

All of these blocks are incorporated in the same unit as represented by the block diagram of Figure 1.

The device under test, DUT is under excitation of a constant current source K Keithley 2400 , when a pulse signal is applied via the HM8030 pulse generator, the D2081UK MOSFET disconnect quickly the DUT from the current source thanks to his low commutation time $(<30 \mathrm{~ns})$. Thus, the voltage drop across the DUT can be measured via a TDS 220 oscilloscope and afterwards the signal will be transferred to the control section by GPIB.

Another source of illumination is added to the constant current source, to investigate the effect of illumination on the carrier lifetime. The source generates a white light with possible adjustable intensity. 


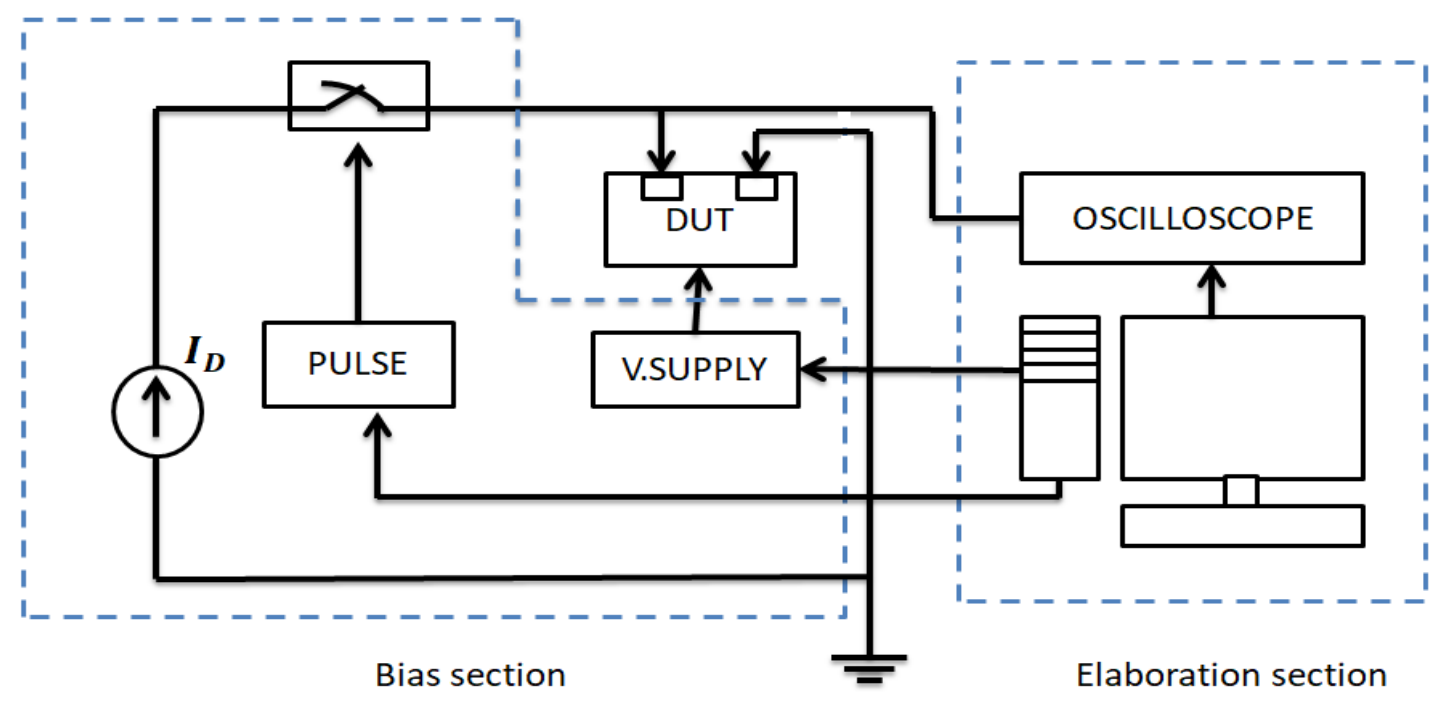

Figure. 1. OCVD System bloc diagram

\section{OCVD System Software}

A Graphical User Interface implemented with LabVIEW [18] permit to send commands and collect data from the OCVD system. A user can initiate the system; manipulate all the parameters that allow him to get a readable signal. The voltage waveform thus obtained is displayed on the screen and data can be saved as CSV files. Moreover, the data will be processed in real time by applying a digital filter and then bypassing and differentiating in order to extract the lifetime value.

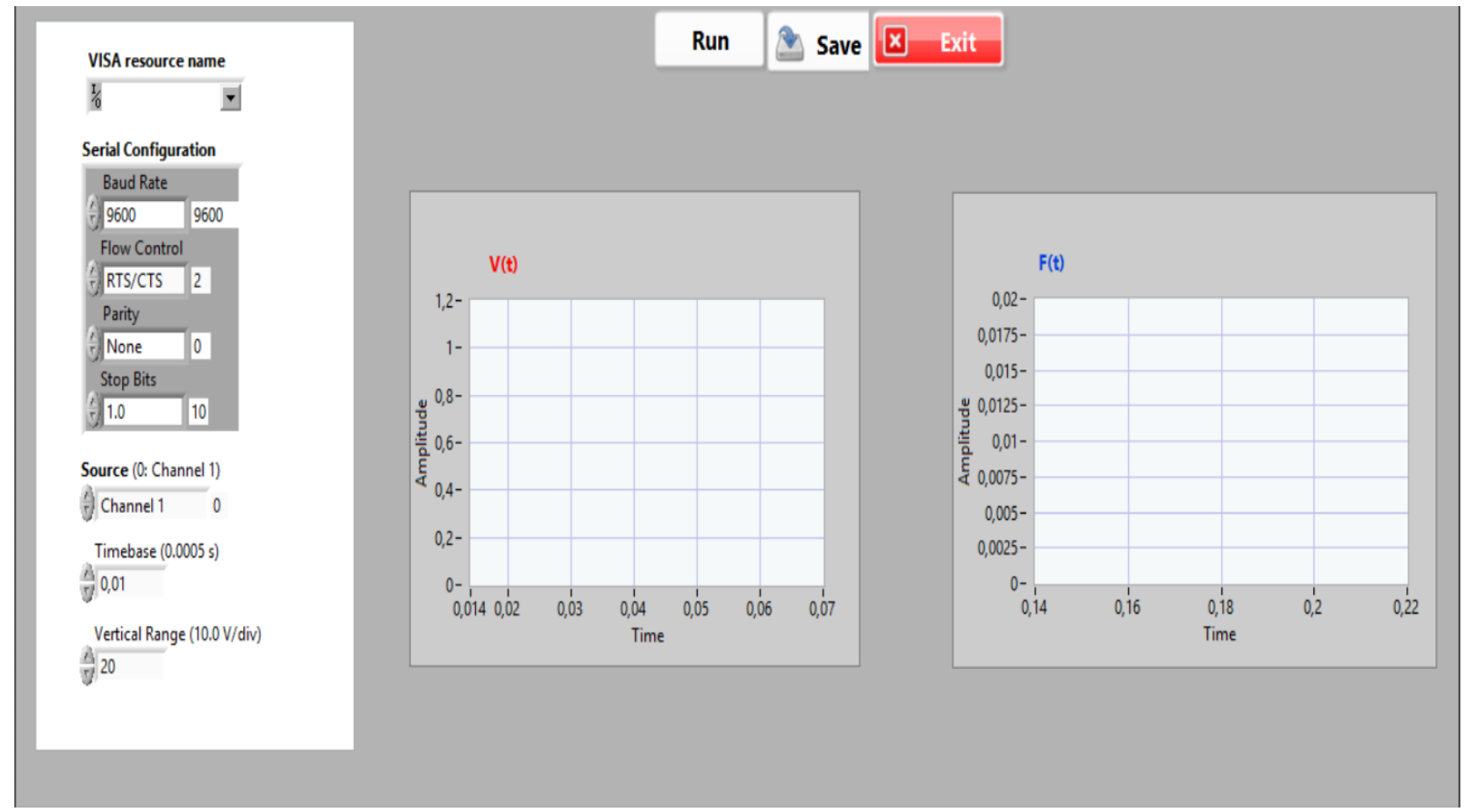

Figure 2. Developed LabVIEW Interface

The algorithm used to filter the signal is the moving average; it consists of calculating the smoothing point $\left(y_{K}\right)_{s}$ being the average of an odd number of consecutive $2 n+1$ points of the raw data [19]. 


$$
\left(y_{K}\right)_{s}=\sum_{i=-n}^{i=n} y_{K+i} /(2 n+1)
$$

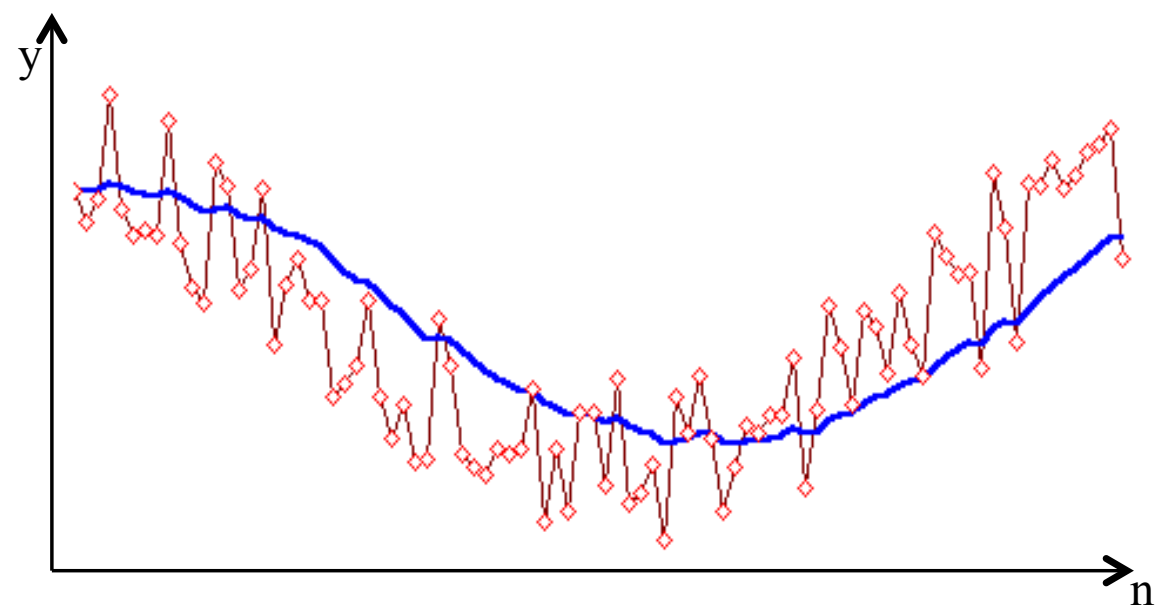

Figure 3 Moving average algorithm applied to an example curve

\section{Experimental results and discussions}

Figures 4 show the $\mathrm{V}(\mathrm{t})$ curves obtained with our OCVD experimental setup using 1N4007 diode at two different current injections, the first at $100 \mathrm{~mA}$ and the second at $1 \mathrm{~A}$. We observe the same behaviour but with different amplitude which is due to the increasing of the generation rate. Our results are similar to those obtained in literature, Lacouture et al. ¡201.

a)

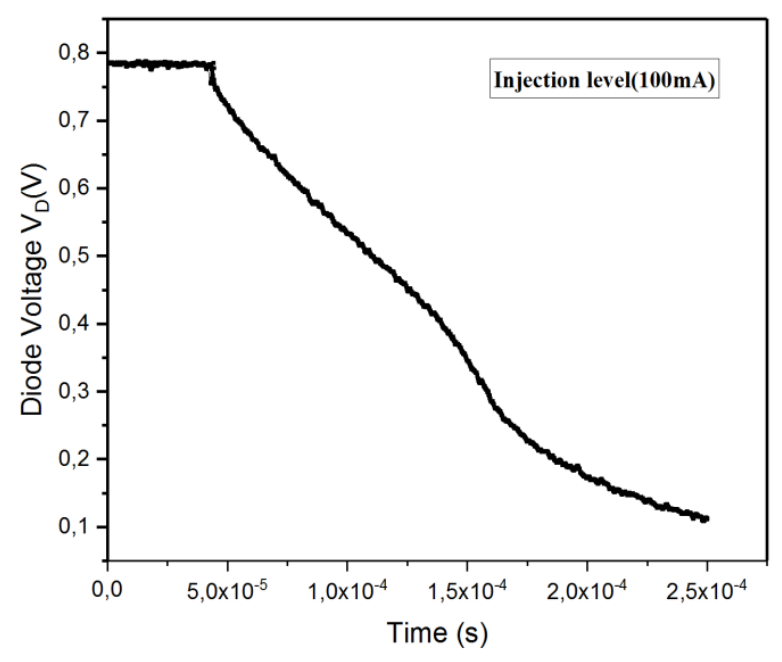

b)

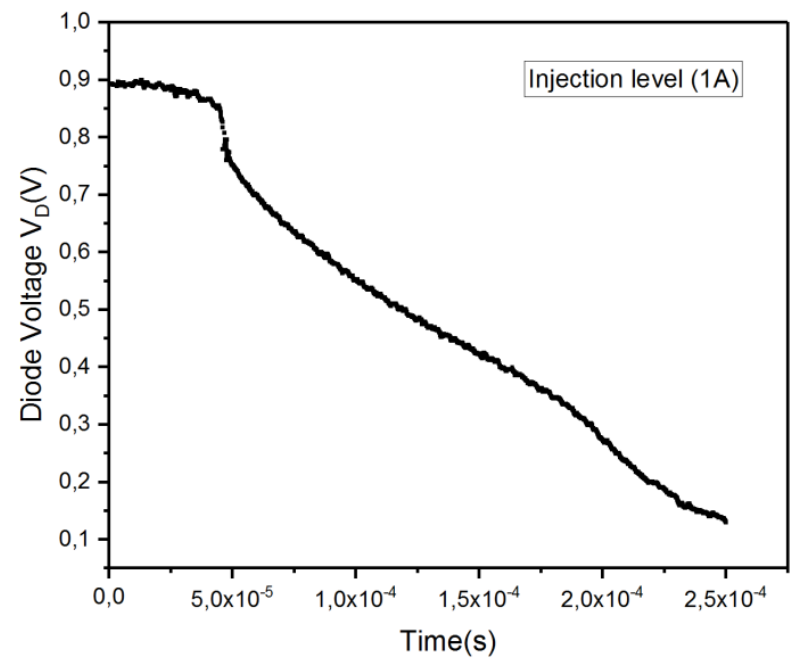

Figure 4: Decay curve V (t) a) at $100 \mathrm{~mA}$ current injection level b) at $1 \mathrm{~A}$ current injection level

In order to investigate the impact of carrier injection level on the lifetime carrier, the light intensity dependence was investigated.

The design of the silicon diode (Vishay 1N4007) is unknown. Thus, we recorded a I-V characteristic and a $\mathrm{C}-\mathrm{V}$ characteristic. The $\mathrm{I}-\mathrm{V}$ curve allows determining the ideality factor and the shunt resistance Rsh while the $\mathrm{C}-\mathrm{V}$ curve allows extracting $\mathrm{N}_{1}$ and $\mathrm{V}_{\mathrm{bi}}$ from an asymmetric p-n junction $[21,22]$. Both curves are presented in Fig. 5. 

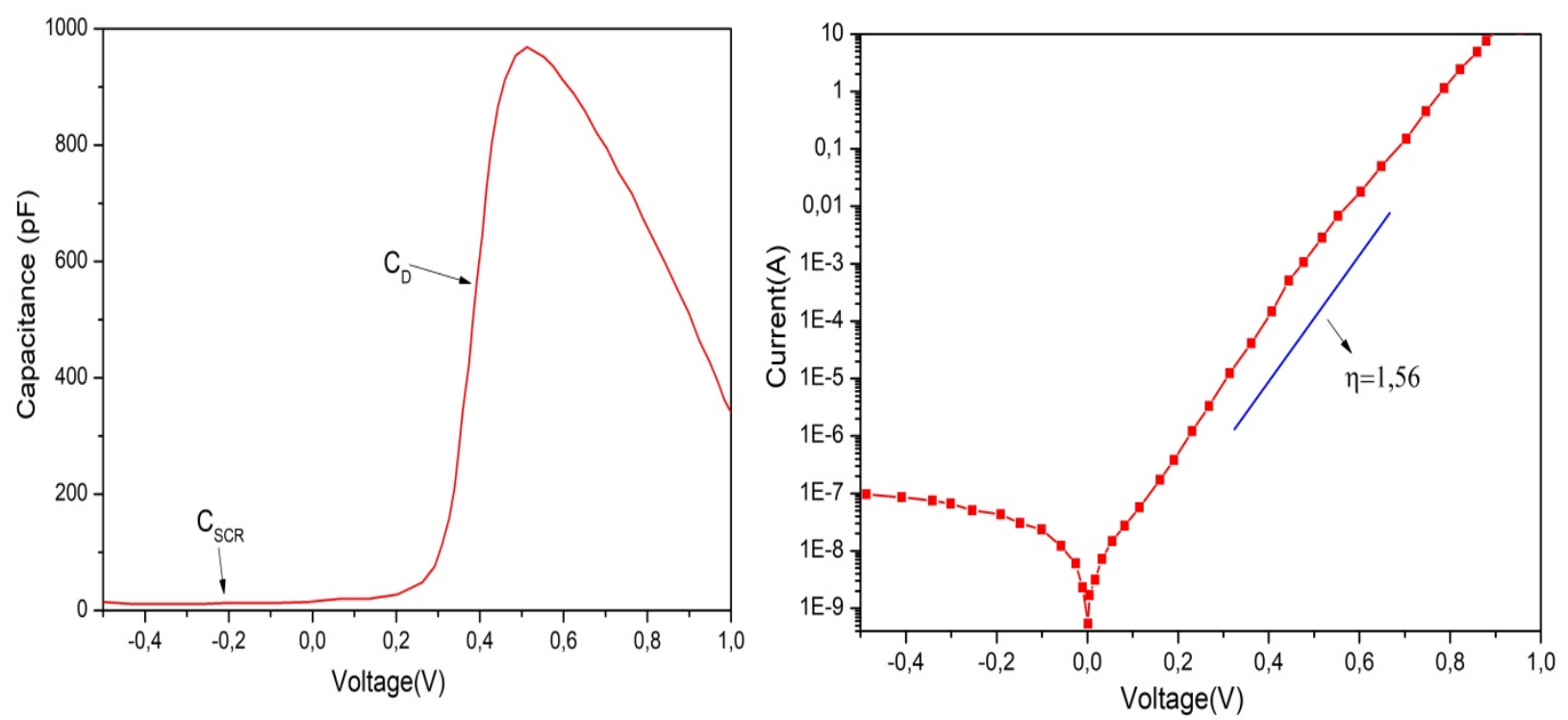

Figure 5. I-V and C-V characteristics of the silicon diode

The ideality factor has been calculated through the local ideality factor $\eta(V)$ [23] with the following equation:

$$
\eta(V)=\frac{q}{K_{B} T} \frac{d V}{d(\ln I)}
$$

where $\mathrm{dV} / \mathrm{d}(\ln \mathrm{I})$ is the slope of the $\ln (\mathrm{I})-\mathrm{V}$ curve at a given voltage represented Fig. 5(b). Then we obtained $\eta=1.56$ by considering the average over the voltage range $[0.2: 0.7 \mathrm{~V}]$. We found considering the voltage range $[-0.6: 0 \mathrm{~V}]$ from the $\mathrm{I}-\mathrm{V}$ curve. Regarding the $\mathrm{C}-\mathrm{V}$ curve, diffusion and SCR capacitances are clearly distinguishable. It is possible to extract $\mathrm{N}_{1}$ and $\mathrm{V}_{\mathrm{bi}}$ by fitting the $\mathrm{C}-\mathrm{V}$ curve with linear regression of $1 / C_{S C R}^{2}[21,22]$ given by

$$
\frac{1}{C_{S C R}^{2}}=-\frac{2 V}{q \in N_{l} A^{2}}+\frac{2 V_{b i}}{q \in N_{l} A^{2}}
$$

where $\mathrm{A}$ is the area of the silicon diode in $\mathrm{cm}^{2}$. We obtained $\mathrm{N}_{1}=2.1910^{12} \mathrm{~cm}^{-3}$ and $\mathrm{V}_{\mathrm{bi}}=$ $0.694 \mathrm{~V}$ for a diode area of $3.14 \mathrm{~mm}^{2}$

As suggested above, the OCVD method allows the characterization of the modification with light of the photocurrent decay (PCD) related to the carriers' lifetime in a photodiode. To highlight this physical phenomena, we applied this to the characterisation of the photocurrent decay in a photodiode EG\&G 444BQ, by adding to the setup a light source varying from $10 \%$ to $30 \%$ of total illumination, corresponding to the range from $0.25 \mathrm{~mW} / \mathrm{cm}^{2}$ to $3 \mathrm{~mW} / \mathrm{cm}^{2}$.

Thus, it is clearly point-out in Figure 6 that, within the OCVD setup as built, the intensity of the light directly influences the photocurrent decay time related to the carriers' lifetime in a photodiode. Nevertheless, a deeper analysis has to be improved to extract all parameters relative to the determination of the carriers's lifetime in photodiode by considering, in addition, the external physical parameters as the temperature, and the wavelength of the light used for the excitation. 


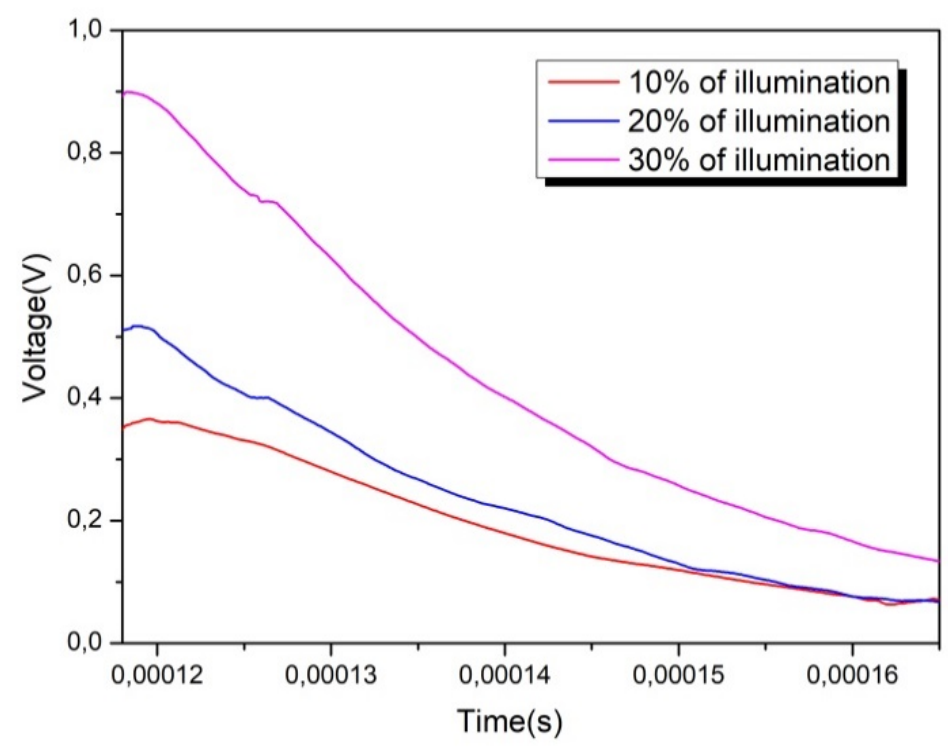

Figure 6. V ( $\mathrm{t}$ ) with excitation of $5 \mathrm{~mA}$, under illumination.

By else, this OCVD technique, that can firstly be considered as a simple experimental technique dedicated to the measurement of carriers' lifetime in semiconductor, allows the characterization of numerous semiconductor devices as diodes and photodiodes, and also for specific characterisations of semiconductor integrated in photovoltaic solar cells.

\section{Summary}

An automated OCVD system was designed allowing data acquisition in a wide range of current injection levels with a low noise the use of recent numerical algorithm permit filtering the signal in each operation. The OCVD measurement was obtained under $300 \mathrm{~K}$ using a packaged commercial 1N4007 PIN HV diode. We also applied this technique to the characterization of the modification with light of the photocurrent decay (PCD) in photodiode. A study of illumination effect on the carrier lifetime is done at three different values. In the aim of studying the effect of defect density on the perovskite solar cells which is one of the limitations of this category of solar cells, the OCVD method will be applied on those cells in future work.

\section{References}

[1] A. Salemi, H. Elahipanah, B. Buono, A. Hallén, J. Ul Hassan, P. Bergman†, G. Malm, C.-M. Zetterling, and M. Östling "Conductivity modulated on-axis 4H-SiC 10+ kV PiN diodes," IEEE 27th International Symposium on Power Semiconductor Devices \& IC's, (ISPSD). pp. 269-272 (2015) doi:10.1109/ispsd.2015.7123441

[2] A.A. Ogunniyi, H.K. O’Brien, M. Hinojosa, L. Cheng, C.J. Scozzie, B.N. Pushpakaran, S. Lacouture, and S.B. Bayne "Analysis of carrier lifetime effects on HV SiC PiN diodes at elevated pulsed switching conditions," in 2015 IEEE Pulsed Power Conference (PPC) pp. 1-6. (2015),

[3] T. Pisarkiewicz*, "Photodecay method in investigation of materials and photovoltaic structures", Opto-electronics review 12(1), 33-40 (2004)

[4] D. V. Lang, "Deep-level transient spectroscopy: A new method to characterize

traps in semiconductors,” J. Appl. Phys. 45(7), 3023-3032 (1974). 
[5] R.A. Sinton and A. Cuevas, "Contactless determination of current-voltage characteristics and minority-carrier lifetimes in semiconductors from quasi-steady-state photoconductance data", Appl. Phys. Lett. 69, 2510-2512 (1996)

[6] D.T. Stevenson and R.J. Keyes, "Measurement of carrier lifetime in germanium and silicon", J. Appl. Phys. 26, 190 (1955)

[7] S. R. Lederhandler and I. J. Giacoletto, "Measurement of minority carrier lifetime and surface effects in junction devices," Proc. IRE, vol. 43, no. 4,pp. 477-483, Apr. 1955.

[8] applets/AppletSmooth/Appl_Smooth2.html

[9] R.A. Sinton and A. Cuevas, "A quasi-steady-state open-circuit voltage method for solar cell characterisation", $16^{\text {th }}$ European Photovoltaic Solar Energy Conference, 1-5 May, Glasgow, UK, 1152-1155 (2000).

[10] D.T. Stevenson and R.J. Keyes, "Measurement of carrier lifetime in germanium and silicon", J. Appl. Phys. 26, 190 (1955).

[11] J. Schmidt and A.G. Aberle, "Accurate method for the determination of bulk minority-carrier lifetimes of mono- and multicrystalline silicon wafers”, J. Appl. Phys. 81, 6186-6199 (1997).

[12] Ch. Berge, J. Schmidt, B. Lenkeit, H. Nagel, and A.G. Aberle, "Comparison of effective carrier lifetimes in silicon determined by transient quasi-steady-state photoconductance measurements", 2nd World Conference and Exhibition on Photovoltaic Solar Energy Conversion, 6-10 July, Vienna, Austria, 1426-1429 (1998).

[13] B.H. Rose and H.T. Weaver, "Determination of effective surface recombination velocity and minority carrier lifetime in high-efficiency Si solar cells”, J. Appl. Phys. 54, 238-247 (1983).

[14] S. Lederhandler, \& L. Giacoletto,. Measurement of Minority Carrier Lifetime and Surface Effects in Junction Devices. Proceedings of the IRE, 43(4), 477-483. (1955). doi:10.1109/jrproc. 1955.277857

[15] https://www.tek.com/keithley-source-measure-units/keithley-smu-2400-series-sourcemeter

[16] https://fr.rs-online.com/web/p/transistors-mosfet/7387720

[17] tek.com

[18] https://www.ni.com

[19] Steven W. Smith, in Digital Signal Processing: A Practical Guide for Engineers and Scientists, 2003

[20] S. Lacouture, J. Schrock, E. Hirsch, S. Bayne, H. O’Brien, \& A.A. Ogunniyi,. An open circuit voltage decay system for performing injection dependent lifetime spectroscopy. Review of Scientific Instruments, 88(9), 095105. (2017). doi:10.1063/1.5001732

[21] C. Van Opdorp, "Evaluation of doping profiles from capacitance measurements," Solid-State Electronics, vol. 11, no. 4, pp. 397-406, Apr. 1968. [Online]. Available: http://www.sciencedirect.com/science/article/pii/0038110168900208

[22] D. K. Schroder, Semiconductor material and device characterization, 3rd ed., 2006.

[23] K. R. McIntosh, "Lumps, Humps and Bumps: Three Detrimental Effects in the CurrentVoltage Curve of Silicon Solar Cells, PhD Thesis U. Melbourne Australia, 2001 "Available https://www.researchgate.net/profile/Keith_Mcintosh3/publication/ 